\title{
Enantioselective Cobalt-Catalyzed Alkene Hydroalkylation
}

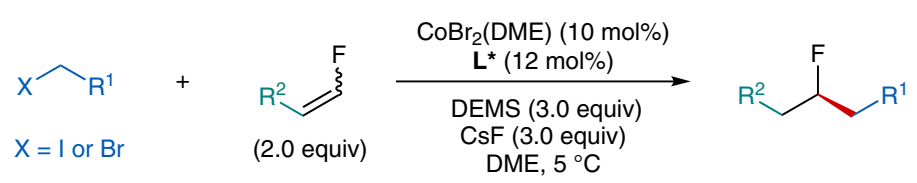

$0.2 \mathrm{mmol}$ scale, 56 examples, up to $90 \%$ yield, up to $99 \%$ ee

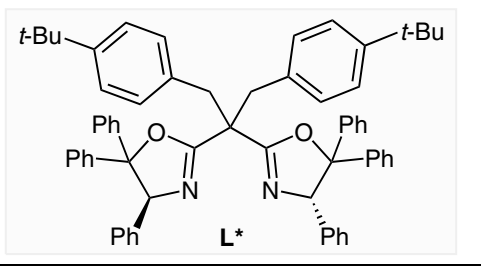

Selected examples:<smiles>O=C(OCCCC(F)CCBr)c1cccs1</smiles><smiles>FC(CCCCl)CCCBr</smiles>

$85 \%$ yield $96 \% \mathrm{ee}^{\mathrm{a}}$ $93 \% \mathrm{ee}^{\mathrm{a}}$<smiles>CCCCC(F)CCCOC(=O)c1ccc(NC(=O)OCc2ccccc2)cc1</smiles>

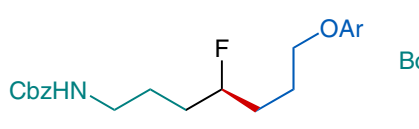

\section{$78 \%$ yield} $93 \%$ ee

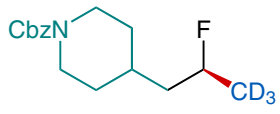

$78 \%$ yield $4 \%$ ee
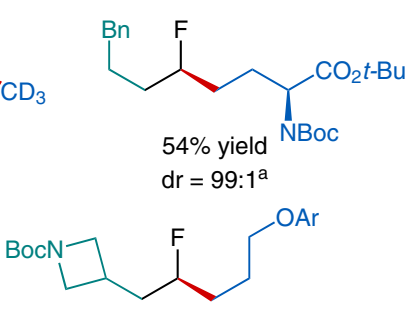

\section{$74 \%$ yield}

$93 \%$ ee

${ }^{a}$ from 1:5.3 (Z/E) monofluoroalkene, ${ }^{b}$ from 19:1 (Z/E) monofluoroalkene, $\mathrm{Ar}=2$-naphthyl

Proposed mechanism:

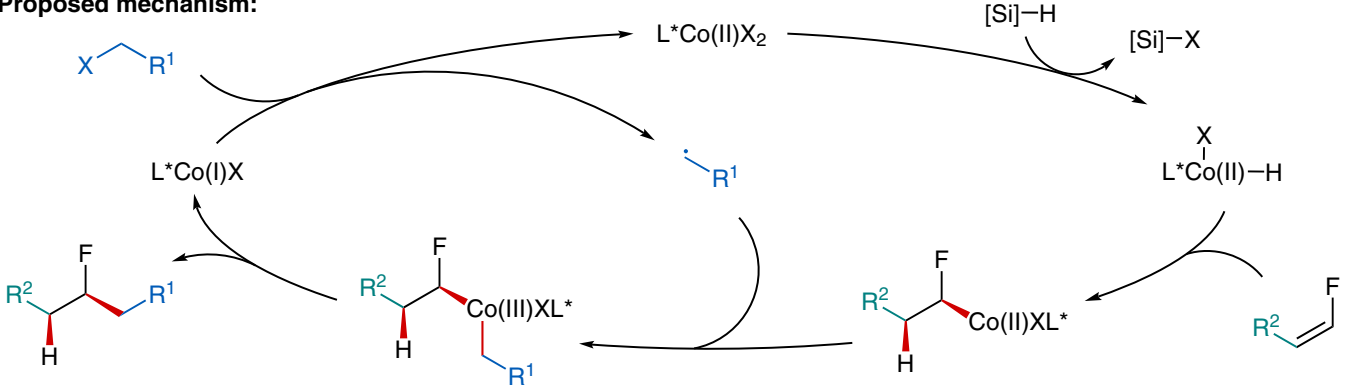

Mechanistic studies:
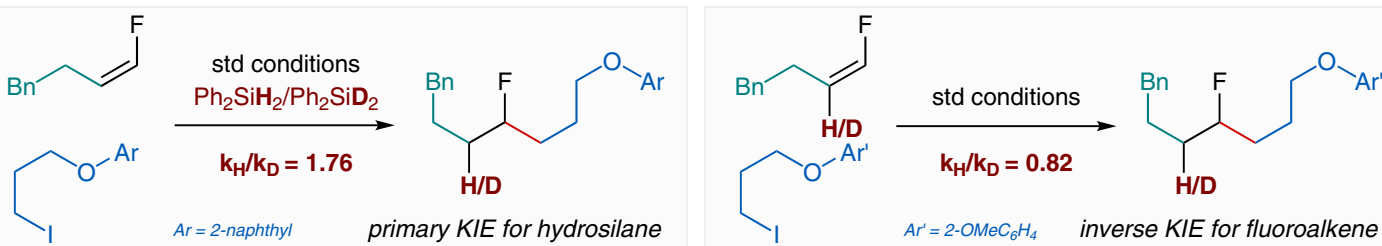

Significance: A stereoselective Co-catalyzed $\mathrm{C}\left(\mathrm{sp}^{3}\right)-\mathrm{C}\left(\mathrm{sp}^{3}\right)$ coupling reaction to access chiral fluoroalkanes has been developed. The reaction exhibits catalyst-controlled enantioselectivity, thereby removing the requirement for substrate auxiliaries. A series of mechanistic and computational studies were conducted to elucidate the mechanism for the transformation.
Comment: The reaction demonstrated high functional group compatibility with regards to both coupling partners. Radical clock experiments support a radical pathway from the alkyl halide. Kinetic studies suggest the reaction proceeds through an irreversible rate-limiting syn-hydrometalation of the $\mathrm{Co}-\mathrm{H}$ intermediate across the $\pi$-system. 